\title{
Textualidade, currículo e investigação
}

\author{
Textuality, curriculum and investigation
}

\author{
Textualidad, currículo e investigación
}

\author{
ÉrikA Virgílio RODRIGUES DA CUNHA* \\ Hugo Heleno Camilo CoSta** \\ TALITA VidAl PEREIRA****
}

\begin{abstract}
RESUMO
Este artigo é resultado de uma reflexão que focaliza as formas pelas quais se tem incorporado a ideia de texto como o tecido que compõe heterogeneamente múltiplas camadas de leitura, conforme proposto por Derrida, com a apropriação de Ernesto Laclau para pensar o social como texto. O objetivo é explicitar os pressupostos teóricos antirrealistas que sustentam a pesquisa no campo do currículo na perspectiva discursiva, assumindo, com Lopes e Macedo, Laclau e Derrida, que, na textualidade geral, nada pode estabilizar definitivamente a significação. Defende-se que todo esforço por impor um fundamento ao social com a pretensão de suturar a significação está, invariavelmente, fadado ao fracasso. A investigação da e na textualidade é sustentada como potente por abrir às remessas que perturbam o querer de toda objetividade, ao permitir demonstrar a contingência como o que instaura o momento de uma inscrição, de uma interpretação composta pela articulação de diferenças como a reinvindicação de uma presença ausente. Sustenta-se, nessa via, que toda formação discursiva, todo discurso de reparação social, se constitui implicado por uma radical indecidibilidade, jamais eliminada no jogo da significação.
\end{abstract}

Palavras-chave: Currículo. Textualidade. Discurso.

\begin{abstract}
This article is the result of reflecting on how we have incorporated the idea of a text as the fabric that makes up multiple layers of reading, as proposed by Derrida, borrowing from Ernesto Laclau to think the social as text. Our goal is to explicit the anti-realist standpoints that support our research, agreeing with Laclau and Derrida, Lopes and Macedo, that, in general textuality, nothing can with any finality establish a meaning. Therefore, we seek to highlight that every effort in imposing a standard with the intention of grasping that meaning is, invariably, destined to fail. The research on and in the textuality wants to highlight the possibilities of disturb the objectivity as a last truth or grounding. This perspective let us think about the contingency as a way that open new inscriptions/writings, new interpretations, produced in an articulation of differences as reclaims of a non-presence. By this way, we defend every discursive formation as built in a radical indecidibility, never erased in the meaning game tension.
\end{abstract}

Keywords: Curriculum. Textuality. Discourse.

\section{RESUMEN}

Este artículo resulta de una reflexión que se centra en las formas por las cuales se ha incorporada la idea de texto como el tejido que compone de manera heterogénea múltiples capas de lectura, según propuesto por Derrida, con la apropiación de Ernesto Laclau para pensar lo social como texto. El objetivo es explicitar las bases teóricas anti-realistas que apoyan la investigación en el ámbito del currículo en la perspectiva discursiva, asumiendo, con Lopes y Macedo, Laclau Y Derrida, que, en la textualidad general, nada puede estabilizar definitivamente la significación. Se defiende que todo esfuerzo por imponer un fundamento al social con la pretensión de suturar la significación está, invariablemente, condicionado al fracaso. La investigación de y en la textualidad se muestra como potente por abrir a las remesas que perturban el querer de toda la objetividad, al permitir demostrar la contingencia como lo que instaura el instante de una inscripción, de una interpretación compuesta por la articulación de diferencias como la reivindicación de una presencia ausente. Se sostiene, en esa dirección, que toda la formación discursiva, todo el discurso de reparación social, se constituye implicado por una radical indecidibilidad, jamás eliminada en el juego de la significación.

Palabras clave: Currículo. Textualidad. Discurso.

* Doutora em Educação pela Universidade do Estado do Rio de Janeiro no Programa de Pós-Graduação em Educação (PROPEd), Professora Adjunta do Departamento de Educação e do Programa de Pós-Graduação em Educação - Mestrado (PPGEdu), da Universidade Federal de Mato Grosso, Campus de Rondonópolis.E-mail: <erikavrcunha@gmail.br>.

**Doutorando em Educação pela Universidade do Estado do Rio de Janeiro no Programa de Pós-Graduação em Educação (PROPEd), Professor Substituto do Departamento de Formação de Professores da Faculdade de Educação da baixada Fluminense, da Universidade do Estado do Rio de Janeiro, Campus Duque de Caxias. Bolsista Faperj Nota 10.E-mail: <hugoguimel@yahoo.com.br>.

***Doutora em Educação pela Universidade do Estado do Rio de Janeiro no Programa de Pós-Graduação em Educação (PROPEd), Professora Adjunta do Departamento de Formação de Professores e do Programa de Pós-Graduação em Educação, Cultura e Comunicação - Mestrado (PPGECC) da Faculdade de Educação da baixada Fluminense, da Universidade do Estado do Rio de Janeiro, Campus Duque de Caxias. E-mail: <p.talitavidal@gmail.com>. 


\section{INTRODUÇÃO}

Sob filiação das perspectivas pós-estruturalista e pósfundacionalista, esta discussão se articula às reflexões produzidas no campo do currículo ao se apresentar como alternativa às abordagens estruturais críticas de investigação. As abordagens estruturais críticas concebem o social a partir de "desníveis" pensados como o resultado da distância entre uma consciência fragmentada do social (uma falsa consciência, um não saber) e uma consciência plena (a visão da totalidade social). Ao entender que tal fissura determina o lugar do sujeito na topografia social desigual, essa perspectiva confirma que a educação deve possibilitar a realização plena da identidade, o que pode significar dominar um conhecimento poderoso (YOUNG; MULLER, 2011), adquirir conhecimentos relevantes e habilidades necessárias para compreender o seu papel na transformação social (MOREIRA; CANDAU, 2007), dentre outras significações.

De distintos modos, a preocupação com o conteúdo da formação da identidade constituiu hegemonicamente os argumentos no campo, mantendo o alinhamento entre sujeito e sociedade e orientando uma lógica prescritiva de produção curricular. Supondo o conhecimento como verdade, entendendo ser $o$ conhecimento $a$ expressão do mundo, as perspectivas estruturais críticas asseguram que o conhecimento vai garantir a formação para as necessidades sociais, humanas; instruir, humanizar, sensibilizar, instrumentalizar cognitivamente, eliminar as diferenças ou realizar a igualdade, libertar das opressões, emancipar, conscientizar, informar; prover $o$ desenvolvimento social, tecnológico, científico e econômico do país, garantir $o$ trabalho, criar as condições para $a$ justiça social, permitir $a$ participação responsável, incluir etc., servindo também como medida de conhecer, saber, ser, medida $d a$ qualidade, $d a$ aprendizagem, $d a$ educação/ensino (MACEDO, 2012; BIESTA, 2013).

Com essa ênfase na centralidade do conhecimento, as perspectivas estruturais críticas alinham a produção teórica ao projeto emancipatório de sociedade e, simultaneamente, fiam as promessas de mudança da escola nas políticas de currículo no Brasil (ver, por exemplo, os Parâmetros Curriculares Nacionais, BRASIL, 1997; 1998).

A partir do pós-estruturalismo e do pós-fundacionalismo, tem-se problematizado a transparência na relação com a linguagem nas abordagens estruturais, por entender que a crença nos significados plenos reprime possibilidades outras de se pensar a educação. Como na perspectiva racional habermasiana, por exemplo, nas abordagens estruturais, a concepção transparente de linguagem assoalha a ideia de que há um sentido uno para os objetos e que a linguagem transporta um suposto sentido. Essa transparência não problematizada autoriza a pensar que os problemas educacionais resultam da falta de clareza quanto às proposições curriculares e leva o pensamento educacional, cada vez mais incisivamente, a considerar que a falta de clareza na proposição curricular constitui o problema da má qualidade da educação.

Com o pós-estruturalismo, por sua vez, temos afirmado que o acesso imediato ao mundo, às coisas, ao que se chama de realidade, é algo impossível, pois o mundo não está (num lá, à nossa espera) para ser decifrado; os significantes (as palavras, os termos) não transportam sentidos plenos, não representam um encaixe ideal entre um referente e a realidade. Temos ponderado que a retórica dilui a ilusão de um acesso não mediado aos objetos e questionado o realismo envolvido nessa lógica essencialista ao sustentar a noção de que há um sujeito (um cogito) a ser formado e uma sociedade a ser conciliada como totalidade.

Ao questionarmos a ideia de essência, a unidade do signo, recusamos a suposição comum de que se pode controlar os efeitos do conhecimento sobre o sujeito e argumentamos que o privilégio do significante conhecimento, em perspectivas estruturais críticas nas políticas de currículo em curso, não projeta qualquer conteúdo inequívoco. Isso tem nos permitido afirmar que a repetição significante faz desse termo privilegiado o lugar vazio de uma inscrição sempre perturbada pela différance, invariavelmente tecida na tradução/traição. Nessa via, temos buscado pensar as questões de currículo no "impulso espantoso de uma inquietação sobre a linguagem - que só pode ser uma inquietação da e na própria linguagem" (DERRIDA, 2011, p. 01).

A partir, sobretudo, de Lopes e Macedo, concebemos currículo como espaço-tempo de fronteira cultural (MACEDO, 2006a), um lugar de enunciação (MACEDO, 2006b), uma prática discursiva (produção cultural) implicada na luta por significação (LOPES, 2013) dos objetos sociais e do próprio currículo. Isso nos tem feito considerar o currículo na relação com a estrutura descentrada, aberta e múltipla, na qual os centros são permanentemente provisórios e o poder não se circunscreve a um ente ou esfera. A relação a uma estrutura descentrada constitui as disputas pela significação (LACLAU, 2011a) como tentativas de impor um centro, um fundamento conjeturado capaz de suturar a estrutura, conter o fluxo da significação, estancar os sentidos, imprimir ordem ao social. Nesse aspecto, temos realçado em nossas discussões que a precariedade da linguagem é o que torna possível a ação política (LACLAU; MOUFFE, 2010), na medida em que faz fracassar toda tentativa de fechamento da estrutura. Desse modo temos constatado que o projeto racional de universalização (uma identidade, uma sociedade), tal como esteado nas abordagens estruturais 
críticas, restringe alternativas educacionais outras, projetadas no/pelo diferir constante à margem de qualquer prescrição/determinação. Não obstante, defendemos ser mais produtivo apostar na ideia de universal como lugar permanentemente aberto à negociação do poder.

Para destacar algumas das questões implicadas nessa discussão, aqui tratamos, inicialmente, a concepção de social como textualização. Enfatizamos as noções derridianas de texto, textualização e tradução como operadores teóricos potentes no sentido de se reconfigurar os objetos sociais e o modo que se empreende a investigação no campo da educação. A discussão é permeada pela tentativa de demonstrar a radicalidade de se considerar os objetos da teorização como inscrições feitas no terreno de uma textualização aberta. Num segundo momento, explicitamos aspectos da teoria discursiva laclauniana que têm nos conduzido, na pesquisa, a romper com perspectivas realistas e essencialistas e, nesse gesto, realçar a pertinência de se defender o lugar do fundamento/universal como vazio, espaço-tempo de permanente negociação (LOPES, 2012).

\section{TEXTO E TEXTUALIDADE}

No pós-estruturalismo desconstrucionista, as noções de palavra, texto, leitura, tradução e autoria sofrem profunda modificação. É em A farmácia de Platão (1991a) e em Gramatologia (2008) que Jacques Derrida, mais incisivamente, contesta a concepção clássica de texto ou seu sentido restrito (escrito ou falado), para defini-lo como o tecido que compõe heterogeneamente (com fios e fios entrelaçados, infinitamente) múltiplas camadas de leitura. Derrida liberta o texto de uma literalidade e o circunscreve em uma textualidade geral. $\mathrm{O}$ gesto derridiano compreende o momento em que o conceito de linguagem se torna transbordamento (DERRIDA, 2008), o momento em que a visão saussuriana da unidade do signo ou da unidade entre significado (sentido, conceito) e significante (palavra ou imagem acústica) se desfaz. Com esse gesto, o filósofo reconfigura o significado, entendendo que este sempre funciona como um significante: o significado, assim como o significante, nunca escapa ao jogo das remessas significantes que constitui a linguagem.

Derrida assevera que o signo, terreno da teleologia, jamais pôde existir antes de uma escritura em geral. Para o filósofo, a escritura é a própria linguagem como produção simbólica, o tecido que reveste todo objeto, toda interpretação, todo veredito. O filósofo franco-argelino realça a escrita como um suplemento do pensamento ou da fala, que trabalha sobre/sob ambos como representação. Contrariando Saussure, Derrida considera que a escrita não é simples reflexo ou figuração da fala/do pensamento, não é uma exterioridade ou uma derivação (do $\left.\log o s^{1}\right)$. Como representação, a escrita se abre a sentidos outros imprevistos porque evoca a presença daquilo que não pode comparecer. Como representação, ela corrompe/ acrescenta/escava e faz transbordar o excesso do sentido sobre o vazio significante.

A escrita, assim pensada, constitui o campo do rastro instituído (DERRIDA, 2008), uma superfície sob a qual nada é capaz de conciliar significado e significante. Nessa impossibilidade de conciliação, de unidade, significante e significado se relacionam - na dimensão do rastro como atos de instituição. Por essa via, Derrida (2008) considera que a grafia - e isso vale não apenas para o sistema alfabético, mas também para o pictográfico, hieroglífico, ideográfico e fonético - reivindica uma presença impossível (de um referente, de uma origem, de um objeto) e, ao mesmo tempo, configura a ausência irredutível de um outro presente transcendental. Essa reivindicação impossível (presença/ausência) perfaz a estrutura implicada pelo arbitrário do signo ou por sua "imotivação" (DERRIDA, 2008, p. 57), por sua condição infinita de tentar ser.

O deslocamento operado pela desconstrução entre a crença na presença plena referida aos termos e a ideia de que termos ou significantes constituem a instância do rastro possibilitam pensar de modo diferente a relação com os objetos e, sobretudo, com a linguagem. Autoriza a pensar, via problematização da intenção, da transparência ou da pretensão de totalidade, os objetos das investigações. Se o signo é sempre um tentar ser infinito e se a suplementação é a única origem possível, é porque nenhum fundamento pode comparecer como tal na significação, a não ser a partir do trabalho de um jogo referencial, que é denegação/condição de todo objeto. Esse jogo referencial compreende a estrutura de objetividade e constitui toda prática de significação como produção social (LACLAU, 2011a).

Ter em tela o trabalho do jogo referencial como estrutura de objetividade, tal como propõem Derrida e Laclau, é dizer que a realidade de todas as coisas (do social) é o próprio rastro. Como a inscrição de uma rasura nunca contida pela oposição presença/ausência, o rastro configura a relação de um dentro com um fora ou a indecidibilidade em toda oposição. Como um estranho inalcançável/inominável que não deixa de comparecer, o rastro inscreve a abertura à enigmática exterioridade - espaçamento - a demarcar a impossibilidade mesma de uma identidade referir-se apenas a si mesma, ao seu interior. Derrida (2008) considera que "o espaçamento como escritura é o vir-a-ser-ausente e o vir-a-ser-

\footnotetext{
Implode a possibilidade mesma de um conceito conexo de verdade que a ordem de uma determinação (consciência) reivindica.
} 
inconsciente do sujeito", o vir-a-ser como possibilidade do sujeito feita-desfeita na deriva, nesse movimento que é também o da emancipação do signo: o trabalho retroativo de constituição do desejo da presença, do desejo (ousamos pontuar) e, com o desejo, da subjetividade.

Este devir - ou esta deriva - não sobrevém ao sujeito que o escolheria ou nele deixaria passivamente arrebatar. Como relação do sujeito a sua morte, este devir é a própria constituição da subjetividade. Em todos os níveis de organização da vida, isto é, da economia da morte. Todo grafema é por essência testamentário. E a ausência original do sujeito da escritura é também a da coisa ou do referente (p. 84 - grifos do autor).

O espaçamento se faz imbricado pelo diferir permanente que impede uma inscrição primeira ou definitiva do sentido (DERRIDA, 1991b). É por não se fazer preso ao sentido que este constitui a estrutura da subjetividade como a relação ao outro. O espaçamento se abre à subjetividade (à alteridade) ao exercitar a irredutibilidade do contínuo diferimento. Essas ponderações permitem pensar a estrutura da linguagem (ou a estrutura do social) como configurada pelo seu caráter performativo. Isso é o mesmo que considerar que toda estrutura de significação se apresenta como o terreno de uma disputa: porque o sentido nunca está lá onde ele é anunciado, o social está sempre por ser feito numa disputa de sentidos, na deriva do rastro, envolvendo palavras, atos, intenções.

Com tal compreensão, afirmamos o social como texto, tendo em conta a materialidade significante e, nela, o próprio rastro impedindo a transparência de qualquer inscrição. Entendemos a linguagem como uma inerradicável mediação entre os sujeitos e o mundo, como a possibilidade de representação de um mundo que não está dado, que se constitui nos jogos significantes como retroatividade. É nesses termos que o texto, tal como pensa Derrida, não é mais a inscrição em uma folha, mas toda estrutura referencial que comporta o jogo das diferenças:

O que eu chamo de "texto" implica todas as estruturas ditas "reais", “econômicas", "históricas", sócio institucionais, em suma, todos os referenciais possíveis. Outro modo de recordar, uma vez mais, que não há extratexto. Isso não quer dizer que todos os referenciais estão suspensos, negados ou encerrados num livro, [...]. Mas isso quer dizer que todo referencial, toda realidade tem a estrutura de um traço diferencial e só nos podemos reportar a esse real numa experiência interpretativa. Esta só se dá ou só assume sentido num movimento de retorno no diferencial (DERRIDA, 1991c, p. 203).

Se pensamos o texto como uma estrutura referencial, concebemos a textualização, por sua vez, como um terreno geral no qual se desborda qualquer inscrição, sentido, origem (DERRIDA, 2011). A textualização reveste todo objeto, mas não se revela num presente, num agora simples e pontual. Na textualização geral, viver é possível somente na relação de morte com o sentido, na tentativa (nunca consumada) de estabilizar o sentido ou o social. O viver se relaciona então à própria impossibilidade de transporte do sentido pela linguagem. Essa impossibilidade torna a linguagem performática, liberta a linguagem de qualquer teleologia ou determinação, permite que a repetição significante, a iteração, comporte tão somente a instância do rastro.

Pela iterabilidade ou repetição significante, o desejo, como tentativa de cumprir uma determinação do sentido, fracassa, faz abrir à imprevisibilidade da própria estrutura de iterabilidade que comporta o signo. Dessa forma, a iterabilidade abre ao acontecimento, à alteridade, ao outro insondável, porque, simplesmente, outro (DERRIDA, 2014). Ela permite que, elipticamente, uma diferença se desvie na repetição que, por não ser pura e simples repetição, põe em marcha o singular, o estranhamento, o inesperado. Ressaltando o movimento da iteração, a repetição significante, o filósofo esclarece que

a diferença é o que faz com que o movimento da significação não seja possível a não ser que cada elemento dito "presente", que aparece sobre a cena da presença, se relacione com outra coisa que não ele mesmo, guardando em si a marca do elemento passado e deixando-se já moldar pela marca da sua relação com o elemento futuro, relacionando-se o rastro menos com aquilo a que se chama presente do que àquilo a que se chama passado e constituindo aquilo a que chamamos presente por intermédio dessa relação mesma com o que não é ele próprio: absolutamente não ele próprio, ou seja, nem mesmo um passado ou um futuro como presentes modificados (DERRIDA, 1991b, p. 45).

Este nada mais é que o movimento da citacionalidade, tal como Derrida nos apresenta. É a condição de o significante persistir e, ao mesmo tempo, de a significação resistir. O significante pode ser citado (iterado) porque não há uma determinação do significado. Nestes termos, a citação interdita qualquer teleologia por autorizar que o significante transite à margem de um significado atual ou de uma origem, por credenciar seu vaguear em contextos múltiplos, alheio à presença de um referente primeiro ou último. É por isso que Derrida (1991b) afirma que a repetição/iterabilidade, motivada pelo desejo de estabilização ou fixação do sentido (desejo de centro), vincula-se à alteridade, vincula o que o significante não $e ́$ a um algo outro, ao diferir que é a condição mesma de todo significante insurgir.

A citacionalidade cria então o contexto como o momento de uma inscrição de diferenças imprevistas, não 
calculadas, que, entrelaçadas, compõem a reivindicação de uma presença ausente (DERRIDA, 1991b). O conjunto dessas diferenças compõe, a seu tempo, uma interpretação disso que é ausente, sendo possível dizer que sempre que um significante é citado abre-se um contexto interpretativo. Derrida assim afirma que não há mais que contextos, contextos sem nenhum centro absoluto de ancoragem, contextos nos quais os significantes, como órfãos, seguem isentos de uma responsabilidade delegada ou de uma consciência clausurante (DERRIDA, 1991b). Essas ponderações do filósofo da desconstrução nos permitem pensar os contextos como construções discursivas, o objeto privilegiado das investigações no campo do currículo. Investigar um contexto discursivo é remeter à parcialidade das posições defendidas na disputa política, à precariedade e à provisoriedade que não podem ser superadas por qualquer fundamento. Isto porque a investigação do contexto, tal como se tem pensado ante a textualização aberta, implica se voltar àquilo que possibilita esse contexto, o que está para além do contexto como sua própria condição.

Na perspectiva da textualidade derridiana, o contexto emerge de um corte antagônico na significação que sinaliza um momento de interpretação (a produção discursiva da realidade) e, simultaneamente, o exterior que margeia, provisoriamente, os limites de tal interpretação. Se um contexto é composto por uma pluralidade de presenças/ diferenças que organizam uma inscrição (um sentido, uma estrutura, um sistema), esta é possível na medida em que uma entre tais diferenças é expulsa do conjunto diferencial.

Ao considerar o campo da discursividade (da textualização geral) como o terreno de constituição das políticas, Laclau (2011a) explicita como as políticas emergem implicadas por antagonismo e exclusão. Ao se voltar a preocupações distintas das de Derrida, o teórico argentino dele se aproxima para afirmar o exterior constitutivo como a possibilidade provisória do sistema, da significação, do contexto, num movimento que nunca é capaz de abarcar a totalidade social, por já estar implicado, ele mesmo, numa exclusão. A exclusão não pode ser superada, eliminada, porque sem ela não há contextos ou significação. Ao mesmo tempo que a exclusão constitui o sistema, também mostra a parcialidade de uma inscrição: nenhum sentido (significação, sistema ou estrutura) pode se fechar em si, sobreviver fora de uma relação com algo. O contexto (a estrutura) compõe a interpretação apenas na relação de um dentro com um fora, como a inscrição que, ao ser bordada, desborda-se por esse exterior, por esse outro, que ela sequer pode controlar.

Para a investigação, o contexto compõe a suposição de um sentido provisório, tecido na disputa antagônica pela significação que jamais se estabiliza. Se um referir-se ao sentido é possível na relação de um dentro com um fora, não obstante, nenhuma fixação do sentido se consolida, na medida em que a possibilidade de o significante ser repetido opera deslocamentos contínuos na significação. Isso nos tem feito considerar que nunca se está diante de (ou nunca conjecturamos) apenas um contexto quando mergulhamos no trabalho de compreender dada luta política no campo curricular. A impossibilidade de abarcar todos os contextos possíveis numa investigação diz respeito à incapacidade de se lidar com os deslocamentos incessantes na significação. Por isso mesmo a investigação é sempre a conjetura de um contexto (ou de alguns poucos contextos) que não pode e não intenciona corresponder à totalidade, tampouco se apresenta como um programa capaz de estabilizar a significação.

A investigação de contextos discursivos tal como temos pensado com Laclau, no máximo, afirma os contextos como estabilizações precárias e provisórias de sentido: na tentativa de estabilizar o social no campo da educação, o currículo tende a ser constantemente pensado a partir de um fundamento que, nesses termos, não é mais que uma função de centro a comandar o desejo de ordenação social, o desejo de realização plena da educação, da identidade, da sociedade. É, então, no registro dessa abertura radical $a ̀$ e $d a$ linguagem que temos buscado conduzir a investigação no campo do currículo, entendendo-o como um texto que nunca consegue saturar a identidade do leitor ao qual se destina (LOPES; MACEDO, 2011) e que, igualmente, temos afirmando o social como textualidade. Nestes termos, tem sido importante considerar que, em meio à sedimentação de visões cristalizadas sobre o social, diferentes lutas políticas por significar o currículo têm emergido como disputas por hegemonização de determinadas leituras sobre a educação (Idem).

Entendemos que a investigação $d a$ e $n a$ textualidade é potente por abrir - ao revolver sedimentações sociais às remessas que perturbam o querer de toda objetividade. A investigação permite demonstrar, defendemos, a contingência como o que instaura o momento de uma inscrição, de uma interpretação composta pela articulação de diferenças como a reinvindicação de uma presença ausente (LACLAU, 2011). Possibilita expor a contingência no lugar da teleologia, do trabalho conceitual ou racional de uma comunidade de especialistas. Autoriza a chamar a atenção para o trabalho do rastro, não pelo que ele é (porque o rastro não é nada, não está lá como um corpo a ser apresentado, mas bem enfatiza Derrida, 2011), mas como o trabalho de instituição provisória (e fracassada) de uma relação entre significante e significado.

Pensar o social como textualidade compreende, portanto, situá-lo fora da pretensão de transparência do sentido e como um terreno no qual os objetos são 
permanentemente compostos como discurso (inscrições discursivas). $\mathrm{Na}$ acepção laclauniana que se assumimos, o discurso é "uma totalidade significativa que transcende a distinção do linguístico e do extralinguístico" (1995, p. 05) ou "o terreno primário de constituição da objetividade como tal" (2010, p. 92). Sob este registro, temos dito que a realidade da realidade é a de ser sempre uma tradução, algo subtraído da textualidade geral (ou do campo da discursividade), configurado como representação.

\section{A INVESTigaÇÃo NA TEXTUALIDAdE}

Na afirmação do social como textualidade, sustentamos a Teoria do Discurso laclauniana como abordagem teóricoestratégica de investigação, sobretudo a partir do trabalho de Alice Casimiro Lopes e de Elizabeth Macedo no campo do currículo. Para a Teoria do Discurso, "as categorias linguísticas como as distinções significante/significado e sintagma e paradigma (...) deixam de pertencer a uma disciplina regional e passam a definir relações que operam no próprio terreno de uma ontologia geral" (LACLAU, 2011b, p. 08). Laclau relaciona linguística, retórica e psicanálise à ideia de que, nesses três níveis de operação que também estão presentes no nível da política, há dicotomias irredutíveis a qualquer fundamento unificado. $\mathrm{O}$ estudioso argentino entende que "al nivel lingüístico es la dicotomía entre sintagmas y paradigmas; al nivel retórico, es aquella entre metonimia y metáfora; al nivel psicoanalítico, entre desplazamiento y condensación; al nivel político, finalmente entre diferencia y equivalencia" (idem, p. 08).

Para a Teoria do Discurso, a atuação desses diferentes níveis se faz implicada à produção do social e do político pela inter-relação de duas lógicas distintas: a lógica da diferença e a lógica da equivalência. Estas compõem movimentos distintos e interdependentes de articulação das diferenças que compõem um contexto. Ao se voltar às políticas específicas, Laclau (2010) considera a articulação como o momento em que demandas diferenciais no social (reivindicações não atendidas) constituem uma formação discursiva, uma cadeia articulatória que, na visão do autor, nada mais é que um contexto de disputa discursiva pela significação do social.

Para explicitar como tais lógicas processam uma formação discursiva, Laclau (2011a) busca em Saussure a ideia da língua como um sistema de diferenças (valores relacionais). Na lógica de Saussure a totalidade da língua está pressuposta em cada ato de significação, porque a totalidade do sistema é algo essencialmente requerido pela significação. Para Laclau (2011a), no entanto, diferentemente de Saussure, a possibilidade do sistema não se encontra em si mesmo como uma totalidade fechada, porque, para ser possível, este precisa mostrar seus próprios limites. O teórico argentino pondera que o limite é o que possibilita ao sistema o mostrar-se a si como bloqueio constitutivo na discursividade e produção da significação. Se o sistema é constituído por diferenças, seu limite se mostra somente a partir de uma diferença interpretada como algo que ameaça o sistema em lograr sua constituição como plenitude (sua realização). Nesse caso, a tradução de uma ameaça entre as diferenças é o que autoriza a expulsão dessa diferença da cadeia e, ao mesmo tempo, tal expulsão é a condição de formação da cadeia articulatória. Dessa forma, Laclau (2011a) afirma que o sistema é constituído por exclusão e antagonismo, na medida em que há a exclusão de uma diferença interpretada como antagônica, ou seja, o impedimento de realização das identidades (diferenças/demandas) de se constituírem plenamente.

É na composição do sistema de significação como um contexto interpretativo do social que as lógicas mencionadas por Laclau entram em operação, constituindo tal contexto como formação discursiva. Se, por um lado, os elementos do sistema comparecem como identidades ou diferenças (particulares), por outro, por serem articuladas a partir da tradução de uma ameaça em comum compondo o interior do sistema (o lado interno da exclusão), tais diferenças se tornam equivalentes umas às outras. Um paradoxo imprime ao sistema uma ambivalência essencial porque

\footnotetext{
Em cada caso, a identidade de cada elemento do sistema é constitutivamente dividida: por um lado, cada diferença expressa a si mesma como diferença; por outro, cada uma delas anula a si mesma enquanto tal ao entrar numa relação de equivalência com todas as outras diferenças do sistema (LACLAU; MOUFFE, 2010, p. 69).
}

Como ressalta Laclau (2011a), a exclusão radical é a condição do sistema e também é o que imprime a toda identidade sistêmica uma divisão, uma ambivalência. É nesses termos que Laclau afirma a impossibilidade de constituição plena de uma identidade, pois a equivalência subverte a diferença. $\mathrm{Na}$ investigação, nessa perspectiva, temos buscado entender como uma formação discursiva se constitui com o trabalho da lógica "equivalencial" e da lógica diferencial. Isto tem implicado considerar os momentos nos quais certos reclames no campo educacional passam a compor demandas curriculares específicas (LOPES, 2012). Mais claramente, investigamos processos de articulação de demandas curriculares distintas, instaurados sempre que uma luta política aciona uma divisão no social, quando uma disputa por significar a educação é composta pela instauração de um antagonismo que divide o social em dois campos distintos. No momento de tal divisão, grupos 
curriculares identificados por suas bandeiras pedagógicas têm suas identidades referenciais borradas pelo momento mesmo da articulação política. Se o antagonismo divide o social em dois campos, se dispara a articulação entre diferenças, ele condensa tais diferenças sobre uma adversa representação, uma nomeação que não é a expressão direta de qualquer particular, tampouco um fundamento que entra em curso como o trabalho conceitual de uma reparação/ordenação.

Tal nomeação tem sido pensada com Laclau (2011a) como o momento em que uma representação é configurada hegemonicamente pela unificação contingente de diferenças, o momento no qual a divisão antagônica subjetiva tais diferenças no interior da fronteira sob tal representação. $\mathrm{O}$ antagonismo compreende o processo retórico de produzir a representação faltosa do social como condição de positivação de dada representação hegemônica. É nesses termos que se tem entendido a luta política como uma disputa discursiva por significação. Como em tais disputas nenhum fundamento pode suturar definitivamente a significação, sua sustentação tende a ser o trabalho glorificante de uma repetição que, não obstante, faz flutuar os sentidos e falhar a significação. A iteração significante não instaura qualquer verdade absoluta, mas uma ambiguidade ou indecidibilidade característica de toda identidade e/ou demanda, que comparece na dependência de uma relação de um dentro com um fora. Se não há positividade alguma em tais demandas/diferenças, é o antagonismo como relação a um fora do limite do sistema que cria a ilusão mesma de uma positivação/identidade.

De tal modo, compreender uma formação discursiva hegemônica pode envolver, como uma das vias de trabalho, a investigação dos sentidos nela hegemonizados, o que implica identificar os pontos nodais, um "nome" em torno do qual demandas diferenciadas se articulam. Para Laclau (2011a), no momento em que um sentido (demanda/ identidade) particular é privilegiado a ponto de se tornar o ponto cego da articulação, o ponto nodal ${ }^{2}$, estabiliza-se provisoriamente o fluxo da significação, o deslizamento incessante de sentidos sobre os significantes e criam-se as condições para leituras/interpretações privilegiadas para/ na a política. Esse fechamento da cadeia de significação (formação discursiva) no ponto nodal produzirá a universalização de um sentido particular, que Laclau (2011a) entende como significante vazio por expressar o caráter vazio dessa significação universal.

\footnotetext{
2 Lopes (2008a, p. 21) esclarece que "ponto nodal é uma expressão criada por Laclau e Mouffe (2001) [Hegemonia e estratégia socialista] para registrar a incorporação da concepção lacaniana de pontos de estofo (capiton points). Para Lacan, na medida em que não existe relação fixa entre significante e significado, o livre e infinito deslizamento do significado - o delírio - é detido pelos pontos de estofo, que fecham provisoriamente a significação".
}

A flutuação dos sentidos, por sua vez, não representa qualquer ameaça, mas é uma condição mesma à hegemonização. Para Laclau (2011a), alguns significantes podem ser vinculados a sentidos específicos na medida em que deslizam "entre diferentes processos de significação, sendo identificados de maneira distintas. Eles catalisam sentidos que expressam demandas específicas em um conjunto da heterogeneidade social" (COSTA; PEREIRA, 2013, p. 297). Não apresentam, segundo Laclau (2011a), uma ambiguidade contingente de sentidos, mas expressam a necessidade de significar a falta: a plenitude ausente no interior da estrutura/da identidade.

É desse modo que temos entendido que uma configuração discursiva não se permite explicar por sua própria estrutura senão por aquilo que lhe é parcialmente exterior (LACLAU, 2011), a marca de sua ambiguidade mesma, da ambiguidade de toda identidade; o fato de ser constitutivamente dividida e dependente da relação de um dentro com um fora, de uma relação antagônica para se constituir. Essa consideração permite sustentar com Laclau e com Derrida que, na textualidade geral, nada pode estabilizar definitivamente a significação. Com isso, temos argumentado que o pensamento racional em torno do currículo, desejoso de impor um fundamento suposto capaz de suturar a significação, está, invariavelmente, fadado ao fracasso, na medida em que, como texto, toda formação discursiva, todo discurso de reparação social se faz em meio à indecidibilidade que nunca é eliminada no jogo da significação. Ante a essa inerradicável indecidibilidade a abordagem discursiva laclauniana situa as possibilidades de compreender (interpretar) o social no desígnio da contingencialidade, afirmando que contingência significa um ente cuja essência não implica sua existência, isto é, pode existir ou não existir. Em outras palavras, a abordagem discursiva pontua que a contingência é a marca fulcral dos processos de articulação característicos de hegemonia em um processo político.

Com tais premissas, buscamos, na investigação, entender quais demandas (discursos pedagógicos/ diferenças) entram em disputa em uma formação discursiva, como leituras particulares sobre o modo de realizar plenamente a educação (desejo de ordenação) e quais forças possibilitam o fechamento da significação na precariedade e transitoriedade. Nas palavras de Lopes (2011), "entender uma formação discursiva significa entender um processo hegemônico: como são definidos os termos de um debate político, quais agendas e ações priorizadas, que instituições, diretrizes, regras e normas são criadas". Temos, incisivamente, nos voltado, grosso modo, a problematizar o pensamento racional que esteia a convicção de que certos fundamentos podem corrigir as mazelas educacionais ao ordenar aquilo 
que, pensado como plenitude na relação transparente com a linguagem, pode conferir ao social uma estabilização, a realização plena da educação, da identidade, da sociedade.

Ante à consideração radical do social como textualização pontuamos que o realismo e o essencialismo (na teoria, na investigação ou nas políticas), coordenados pela ideia de estabilidade da significação, restringem as possibilidades de compreensão do social. Limitam a apenas uma as possibilidades da educação, mormente ao sustentar certa defesa de como o currículo tem de ser, de qual o fundamento ou centro é apto a realizar a educação plena. Interditam, com tal lógica, possibilidades (diferenças) outras em curso, que sequer são percebidas, na medida em que a imposição de um centro é ela mesma a necessidade de uma leitura/explicação estrutural (uma realidade) de uma totalidade harmoniosamente suturada. É tensionando essa lógica, demonstrando como ela é esteada por antagonismos e exclusões que, nas investigações, julgamos pertinente defender o lugar do fundamento/universal como vazio, espaço-tempo de permanente negociação (LOPES, 2012).

Assim ressaltamos, especialmente, a relação não problematizada entre uma concepção de educação como plenitude e certa ideia de conhecimento marcada pela falta. Ao se defender o lugar do fundamento como vazio, não se está, com isso, rejeitando a importância do conhecimento na escola. Diferentemente, estamos realçando as reduções operadas na defesa da centralidade do conhecimento da escola como condição da identidade, a partir de distintos projetos societários. Estamos pondo em questão certo conforto que permite a distintos estruturalismos sustentarem a ideia de que se sabe quais conhecimentos correspondem à consecução da identidade/sociedade desejada. Nesse movimento, nos empenhamos em assinalar que os sentidos pelos quais se disputa no campo do currículo na área educacional nunca constituem a medida exata de um cálculo para os objetos sociais, nem podem ser encontrados fora de um jogo. Nestes termos, afirmamos ser a concepção do social como textualidade potente não apenas para a investigação no campo, mas para a produção de uma relação outra com a educação, com o currículo, com o conhecimento. Uma relação na qual o não fechamento definitivo da significação reporta à condição de ter de decidir, negociar na contingência, sempre, invariavelmente, à margem de qualquer determinação.

\section{REFERÊNCIAS}

BIESTA, G. Say you want a revolution: suggestions for the impossible future of critical pedagogy. Educational theory, v. 48, n. 4, p. 499-510, 1998. Disponível em: <www.periodicos. capes.gov.br>. Acesso em: 27 jan. 2013.
BRASIL. Secretaria de Educação Fundamental. Parâmetros curriculares nacionais - introdução aos parâmetros curri-

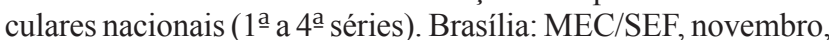
1997.

COSTA, H. H. C.; PEREIRA, T. V. Sentidos de interdisciplinaridade articulados nas políticas de currículo: o caso das disciplinas ciências naturais e geografia. Cadernos de educação (FaE/PPGE/UFPel), n. 44, p. 293-318, 2013 Disponível em: <http://periodicos.ufpel.edu.br/ojs2/index.php/ caduc/article/view/2749>. Acesso em: 7 nov. 2014.

DERRIDA, J. A farmácia de Platão. São Paulo: Iluminuras, 1991a.

DERRIDA, J. Margens da filosofia. Campinas, São Paulo: Papirus, 1991b.

DERRIDA, J. Limited Inc. Campinas: Papirus, 1991c.

DERRIDA, J. Gramatologia. São Paulo: Perspectiva, 2008.

DERRIDA, J. A escritura e a diferença. São Paulo: Perspectiva, 2011 .

DERRIDA, J. El otro [autrui] es secreto porque es otro [autre]. Le monde de l'éducation, entrevista con Antoine Spire, n. 284, sept. 2000. Derrida en castellano. Disponível em: $<$ http://www.jacquesderrida.com.ar/textos/derrida_otro.htm>. Acesso em: 10 jan. 2014.

LACLAU, E. Discourse. In.: GOODIN, R. A., PETTIT, P. (eds.). A companion to contemporary political philosophy. Oxford: Blackwell, v. 2, p. 431-437, 1995.

LACLAU, E. Emancipação e diferença. Rio de Janeiro: EdUERJ, 2011a.

LACLAU, E. La función retórica de las categorías psicoanalíticas. Diecisete: teoría crítica, psicanálisis, acontecimientos. Disponível em: <http://www.diecisiete.mx/ expedientes/psicoanalisis-y-politica/50-la-funcion-retorica-delas-categorias-psicoanaliticas.html>. Acesso em: nov. $2011 \mathrm{~b}$.

LACLAU, E. La razón populista. Buenos Aires: Fondo de Cultura Económica, 2010.

LACLAU, E.; MOUFFE, C. Hegemonía y estrategia socialista: hacia una radicalización de la democracia. 3. ed. Buenos Aires: Fondo de Cultura Económica, 2010.

LOPES, A. C. Discurso e representação na política de currículo: o caso do ensino médio (2003-2010). Projeto de Pesquisa UERJ/CNPq, 2011.

LOPES, A. C. Teorias pós-críticas, política e currículo. Educação, Sociedade \& Culturas, n. 39, p. 7-23, 2013.

LOPES, A. C. Democracia nas políticas de currículo. Cadernos de Pesquisa, v. 42, n. 147, set./dez. 2012, p. 700-715. Disponível em: <http://educa.fcc.org.br/pdf>. http://dx.doi.org/10.1590/ S0100-15742012000300003

LOPES, A. C.; MACEDO, E. Teorias de currículo. São Paulo: Cortez, 2011.

MACEDO, E. Currículo: política, cultura e poder. Currículo sem Fronteiras, v. 6, n. 02, p. 98-133, jul./dez. 2006 a. Disponível em: <www.curriculosemfronteiras.org>.

MACEDO, E. Currículo como espaço-tempo de fronteira cultural. Revista Brasileira de Educação, v. 11, n. 32, maio/ago. 2006b. 
MACEDO, E. Currículo e conhecimento: aproximações entre educação e ensino. Cadernos de Pesquisa, v. 42 n. 147, p. 716-737, set./dez., 2012. http://dx.doi.org/10.1590/S010015742012000300004

MOREIRA, A. F. B.; CANDAU, V. Currículo, conhecimento e cultura. In: Indagações sobre currículo. Ministério da Educação, Secretaria de Educação Básica. Brasília, DF, 2007, 48 p.
YOUNG, Michael; MULLER, Johan. Verdade e veracidade na sociologia do conhecimento educacional. Educação em Revista, Belo Horizonte, MG, v. 45, p. 159-196, jun. 2007.

Submetido em: 07/01/2015

Aprovado em: 18/02/2016 